\title{
Nu-DESC DK: the Danish version of the nursing delirium screening scale (nu-DESC)

Daniel Hägi-Pedersen ${ }^{1 *} \mathbb{D}$, Kasper Højgaard Thybo', Trine Hedegaard Holgersen², Joen Juel Jensen³ Jean-David Gaudreau ${ }^{4}$ and Finn Michael Radtke ${ }^{1,5}$

\begin{abstract}
Background: Delirium is one of the most common complications among elderly hospitalized patients, postoperative patients and patients on intensive care units with a prevalence between 11 and $80 \%$. Delirium is associated with higher morbidity and mortality. Reliable instruments are required to detect delirium at an early time point. The Nursing-Delirium Screening Scale (Nu-DESC) is a screening tool with high sensitivity and good specificity. However, there is currently no official translation after ISPOR guidelines of any Danish delirium assessment tools available. Thereby hampering the implementation of 2017 ESA-Guidelines on postoperative Delirium in the clinical routine. The aim of this study is to provide an official translation and evaluation of the Nu-DESC into Danish following the ISPOR process.

Methods: The Nu-DESC was translated after International Society for Pharmacoecomonics and Outcome Research (ISPOR) guidelines to Danish after permission of the original author, and is evaluated by medical staff and finally approved by the original author.
\end{abstract}

Results: All steps of the ISPOR guideline were consecutively followed, without any major problems. The evaluation of the Nu-DESC DK regarding its intelligibility and feasibility showed no statistically significant differences between nurses and medical doctors ratings. The translation was authorized and approved by the original author.

Conclusion: This study provides the Nu-DESC DK, an official Danish delirium screening instrument, which can detect all psychomotor types of delirium.

Keywords: Nursing delirium screening scale, Confusion, Delirium, Screening

\section{Background}

Delirium is one of the most common complications among elderly hospitalized patients. The reported prevalence is between $11 \%$ to $50 \%$ in medical and surgical populations, and up to $80 \%$ patients receiving intensive care [1-3]. Delirium is associated with a high morbidity and a threefold 6-month mortality $[4,5]$. Patients with delirium have higher rates of complications as well as a higher necessity for rehabilitation. It is reported that patients with delirium during hospital stay often have a lower cognitive function one year after discharge [6,7].

Studies have shown that up to $84 \%$ of all delirium cases are not detected in daily clinical routine $[8,9]$.

\footnotetext{
* Correspondence: dhag@regionsjaelland.dk

${ }^{1}$ Department of Anaesthesiology, Næstved Hospital, Ringstedgade 61, 4700

Næstved, Denmark

Full list of author information is available at the end of the article
}

Furthermore, delirium is reported to be preventable in up to $40 \%$ of patients $[10,11]$ The lack of availability of a fast, adequate and evaluated Danish delirium screening instrument divests clinicians of using delirium, as a quality improvement measure as it is recommended in guidelines [11, 12].

There are three subtypes of delirium described.

-The hyperactive delirium is characterized by psychomotor hyperactivity and an increased response to stimulation (1.6\%) [13].

-The hypoactive delirium is characterized by psychomotor retardation and a reduced response to stimulation (43.5\%). [13].

-The mixed type has symptoms from both the hypoactive and the hyperactive form and is the most common subtype (55\%) [14]. 
Especially, the hypoactive form of delirium has been described as being associated with more negative outcomes [15]. Yet, without an adequate delirium instrument foremost patients with hypoactive delirium are often not diagnosed [16].

Gaudreau et al. have developed the nursing delirium screening scale (Nu-DESC) as a nurse based diagnostic instrument for delirium with special focus on hypoactive delirium. In a validation study of 146 patients the $\mathrm{Nu}-\mathrm{DESC}$ showed a high validity (sensitivity $86 \%$, specificity $87 \%$ ). The average time used for screening per patient was less than a minute $[17,18]$, thereby ensuring high feasibility in clinical routine. In relation to the DSM-IV criteria, which were the gold standard for diagnosing delirium, the Nu-DESC has shown good validity [17]. Furthermore it was suggested that the Nu-DESC not only recognizes significantly more cases of delirium, but detects them at an earlier timepoint [19] Additionally, the Nu-DESC can detect hypoactive delirium due to the fifth element focusing and evaluating the psychomotor activity of patients.

The nursing staff spends more time with the patients than other medical professionals. Therefore choosing a nurse based screening instrument is an obvious and important part of implementing Delirium management into the clinical routine [20].

Presently, there is no Danish delirium screening scale available, that has been officially translated to Danish according to the standard of ISPOR guidelines.

\section{Aim and objectives}

The aim of this study was to establish an ISPOR guidelines conform translation and evaluation of the $\mathrm{Nu}-\mathrm{DESC}$ in Danish. Adhering to the recommendations of the Translation and Cultural Adaptation Group of Patient Reported Outcomes (PRO) measures - Principles of Good Practice (PGP) [21] thereby providing a reliable and easy to use delirium screening scale for use in research and clinical routine in Denmark.

\section{Methods}

We choose to translate $\mathrm{Nu}$-DESC after published guidelines [21]. The evaluation of the instrument will be performed by clinicians of two different departments.

\section{Setting and procedure}

The translation and debriefing procedure was performed at the Department of Anaesthesiology, Næstved Hospital, Denmark. The evaluation took place at the Department of Anaesthesiology and Department of Orthopaedic Surgery, Næstved Hospital, Denmark. We followed the International Society for Pharmacoecomonics and Outcome Research (ISPOR) guidelines [21] in order to have a reproducible translational process. The translation procedure was defined in advance, with all the steps of the translation and evaluation process. The team of translators defined the timeframe and administrative aspects as well as performed the translation and the evaluation of the instrument.

\section{The translation process}

The International Society for Pharmacoecomonics and Outcome Research (ISPOR) has set up a task force for the development of guidelines for translation and cultural adaptation of patient-reported outcome measures [21]. After reviewing 12 official guidelines, including the World Health Organization (WHO) standard, they published a report for scientific accurate practice for translation of measuring instruments. The 10 steps of the ISPOR guidelines are shown in Table 1.

\section{Statistics}

The following characteristics of the participants were documented: gender, occupational group, clinical working place. Mann-Whitney-U-Test was performed for differences between the professional groups. Data was analysed with SPSS version 21 (SPSS, Chicago, IL, USA).

\section{Results}

All ISPOR recommended steps were followed consecutively. And no relevant problems were encountered at any step.

Table 1 Steps of ISPOR guidelines for translation

\begin{tabular}{|c|c|c|}
\hline \multicolumn{3}{|c|}{ Steps } \\
\hline 1 & Preparation & $\begin{array}{l}\text { Obtain permission to use instrument } \\
\text { and involvement of original author }\end{array}$ \\
\hline 2 & Forward Translation & $\begin{array}{l}\text { Development of at least two } \\
\text { independent forward translations }\end{array}$ \\
\hline 3 & Reconciliation & $\begin{array}{l}\text { Reconciliation of the forward } \\
\text { translations into a single forward } \\
\text { translation }\end{array}$ \\
\hline 4 & Back Translation & $\begin{array}{l}\text { Back translation of the reconciled } \\
\text { translation into the source language }\end{array}$ \\
\hline 5 & Back Translation Review & $\begin{array}{l}\text { Review of the back translations } \\
\text { against the source language }\end{array}$ \\
\hline 6 & Harmonization & $\begin{array}{l}\text { Harmonization of all new translations } \\
\text { with each other and the source } \\
\text { version }\end{array}$ \\
\hline 7 & Cognitive Debriefing & $\begin{array}{l}\text { Cognitive debriefing of the new } \\
\text { translation, with } 5-8 \text { healthcare } \\
\text { professionals }\end{array}$ \\
\hline 8 & $\begin{array}{l}\text { Review of Cognitive Debriefing } \\
\text { Results and Finalization }\end{array}$ & $\begin{array}{l}\text { Cognitive debriefing results are } \\
\text { reviewed and the translation finalize }\end{array}$ \\
\hline 9 & Proofreading & $\begin{array}{l}\text { The finalized translation is } \\
\text { proofread }\end{array}$ \\
\hline 10 & Final Report & $\begin{array}{l}\text { Report is written on the } \\
\text { development of the translation }\end{array}$ \\
\hline
\end{tabular}




\section{Preparation}

After agreement and consent from Jean-David Gaudreau the translation process into the Danish language was started.

\section{Forward translation}

After initial distribution of the tasks, three medical doctors and one nurse performed three separate forward translations from English to Danish, all independently and without interference from one another.

\section{Reconciliation}

The translations were then merged in one preliminary version. The Danish version was adapted to a clinical setting without changing the meaning. Each phrase was discussed carefully, compared between the four translations to find the most accurate and fitting phrase. The final wording was consented, when all translators after agreed unanimously. The phrase "reaction is deferred" was one of the phrases, which challenged the translators to find the clinically appropriate phrase in Danish. Several different wordings were tested in the process finally honing in on one clinically phrase that all translators consented to unanimously.

\section{Back translation}

The preliminary version was then back translated into English by an experienced and certified language teacher without knowledge to the original English version. This back translation was then sent back to the authors.

\section{Back translation review}

The back translation of the preliminary Danish version was then thoroughly compared with the original text in regard to the necessity of performing adjustments. This back translation showed no substantial deviations from the original after close comparison and assessment performed by the translating authors.

\section{Harmonization}

The English back translation was then sent to the original author Jean-David Gaudreau for inspection and final approval. Jean-David Gaudreau assessed the back translation in respect to conformity of content and language as well as in regard to the agreement with the original version. The final step of the translation was then approved.

\section{Cognitive debriefing}

The authorized Danish version underwent a structured evaluation process by clinical staff. The evaluation team consisted of 20 nurses and doctors from two different specialties and wards (Table 2). All medical doctors were employees of the department of anaesthesiology (3 consultants and 1 resident). The nurses were all registered
Table 2 Characteristics of the participating staff of the cognitive debriefing

\begin{tabular}{llll}
\hline & & Frequence & Percent \\
\hline Sex & Male & 3 & 15.0 \\
& Female & 17 & 85.0 \\
Professional group & MD & 4 & 20.0 \\
& Nurse & 16 & 80.0 \\
Working place & Orthopaedic ward & 10 & 50.0 \\
& Recovery room & 10 & 50.0 \\
\hline
\end{tabular}

nurses, with several years of clinical experience. All staff evaluating the $\mathrm{Nu}$-DESC got the $\mathrm{Nu}$-DESC DK on paper and an evaluation form to rate the instrument.

\section{Review of cognitive debriefing results and finalization}

The individual items of the test were evaluated in regard to understand ability, both in language and content. In addition, feasibility and usability were evaluated. Each item was rated on a 6 step Likert scale (strongly agree, agree, slightly agree, slightly disagree, disagree, and strongly disagree). The evaluation of the Nu-DESC DK performed by the two professional groups and two different specialties showed no fundamental difficulties in relation to content or language. The evaluation also revealed that all elements are readily usable.

There were no significant differences between the evaluations of the nursing staff and the medical doctors (Table 3).

\section{Proofreading}

The finalized version was proofread by three of the translators.

\section{Final report}

Three of the authors reviewed the result as well as the whole process of translation. After the final positive evaluation and due to the good results of the cognitive debriefing the authors approved the Danish version of the $\mathrm{Nu}$-DESC thereby completing the process suggested by the ISPOR guidelines.

The final and approved version of Nu-DESC DK (Fig. 1) is now ready for clinical and scientific use in Danish speaking countries.

\section{Discussion}

This study provides the first official Danish translation of a delirium screening instrument according to the ISPOR guidelines. We followed the guideline recommendations thoroughly. A consecutive evaluation of the $\mathrm{Nu}$-DESC DK by potential future users showed most promising results in regard to clearness of wording and feasibility. 
Table 3 Results of the cognitive debriefing Mann-Whitney $U$ test

\begin{tabular}{|c|c|c|c|c|c|}
\hline \multirow[t]{2}{*}{ Item } & & \multirow[t]{2}{*}{ Criteria } & \multicolumn{2}{|c|}{ Professional Group } & \multirow[t]{2}{*}{$P$-Value } \\
\hline & & & $\overline{M D}$ & Nurse & \\
\hline \multirow[t]{4}{*}{ Disorientation } & Understanding & Language & 4,75 & 3,94 & 0,290 \\
\hline & & Content & 5,25 & 4,19 & 0,099 \\
\hline & Feasibility & Time & 5,50 & 5,00 & 0,641 \\
\hline & & Usability & 5,33 & 4,56 & 0,487 \\
\hline \multirow[t]{4}{*}{ Inappropriate behaviour } & Understanding & Language & 4,75 & 5,31 & 0,820 \\
\hline & & Content & 4,75 & 5,31 & 0,820 \\
\hline & Feasibility & Time & 5,00 & 5,31 & 0,437 \\
\hline & & Usability & 5,25 & 5,40 & 0,810 \\
\hline \multirow[t]{4}{*}{ Inappropriate communication } & Understanding & Language & 4,50 & 4,94 & 0,494 \\
\hline & & Content & 5,00 & 4,94 & 0,892 \\
\hline & Feasibility & Time & 4,75 & 5,27 & 0,411 \\
\hline & & Usability & 4,75 & 5,00 & 0,810 \\
\hline \multirow[t]{4}{*}{ Illusions/Hallucinations } & Understanding & Language & 5,75 & 5,50 & 0,963 \\
\hline & & Content & 5,75 & 5,50 & 1000 \\
\hline & Feasibility & Time & 5,75 & 5,56 & 0,682 \\
\hline & & Usability & 5,75 & 5,60 & 0,810 \\
\hline \multirow[t]{4}{*}{ Psychomotor retardation } & Understanding & Language & 5,75 & 5,06 & 0,494 \\
\hline & & Content & 5,75 & 5,19 & 0,494 \\
\hline & Feasibility & Time & 5,75 & 5,19 & 0,335 \\
\hline & & Usability & 5,75 & 5,07 & 0,357 \\
\hline
\end{tabular}

Assessment of the test items relative to understanding and feasibility. Rating on a 6 step scale (strongly agree, agree, slight agree, slight disagree, disagree, strongly disagree). Presented are the means of the evaluation of the two groups. Analysis of the group difference of the single items with Mann-Whitney-U-Test. Statistic significance level $p<0,05$

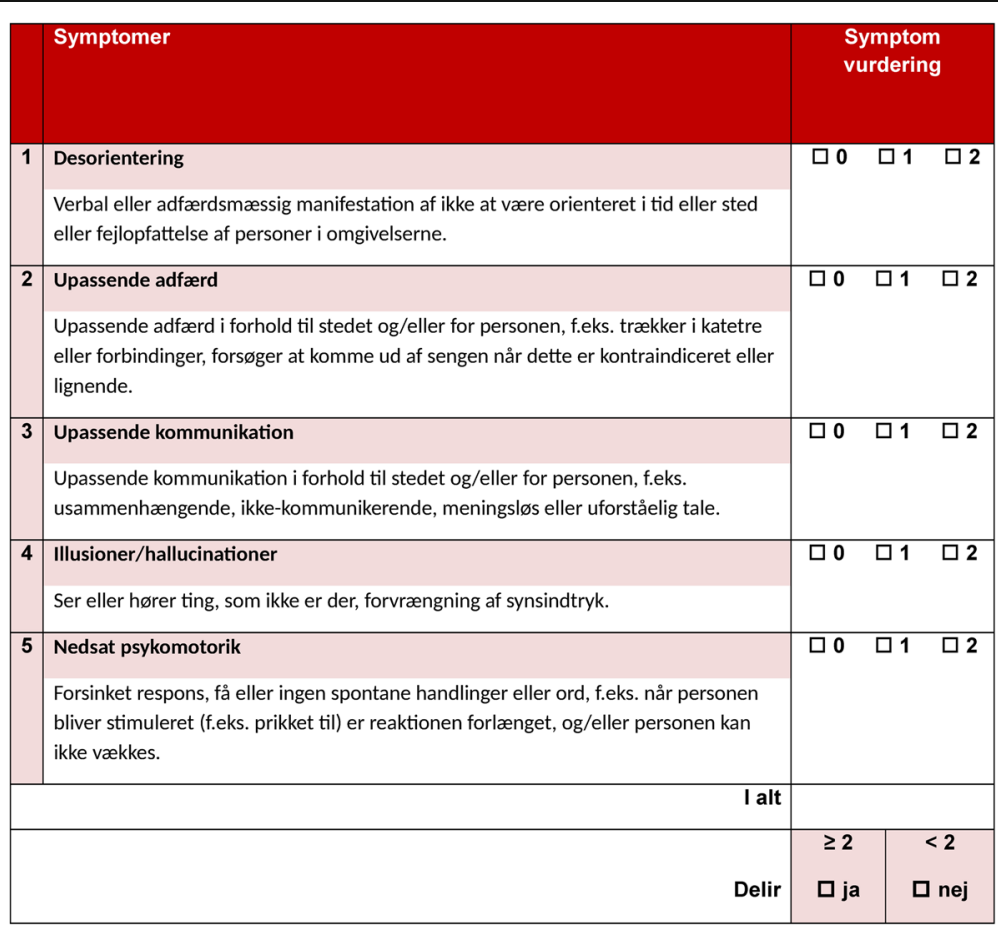

Fig. 1 Nu-DESC DK (Nursing-DElirium SCore Denmark) 
Our process of the translation procedure followed the guidelines of the Translation and Cultural Adaption Group (TCA Group) and the authors had contact with the author of the original instrument. The process of the ISPOR guidelines guarantees that the translation preserves the concept and the intention of the original instrument.

With permission of the original author, the translation after the Guidelines of the Translation and Cultural Adaptation Group (TCA) and after the principles of the International Society for Pharmacoeconomics and Outcome Research (ISPOR) [21] was done to Danish.

Our evaluation showed that the Nu-DESC DK is comprehensible and feasible. There was no significant difference between the evaluation results from the nursing staff and medical doctors', which suggests that the tool is equally usable by both groups.

The Nu-DESC DK is, to the best of our knowledge, the first Danish delirium screening tool translated from the original language following ISPOR-guidelines. It has been authorized by the original author and is free for all interested parties to use.

Delirium is the most common psychiatric diagnosis in elderly hospitalized patients as well as in the postoperative setting and on intensive care units, with prevalence's from $11 \%$ to $50 \%$ [1-3]. The diagnosis of delirium can be challenging due to the different forms of delirium, and due to the fact that delirium can fluctuate during the course of a day. That is the reason why in the daily clinical routine the detection rate of delirium is usually low $[8,9]$. The nursing staff plays a central role in detecting delirium [20]. The availability of an easy to use, nurse based delirium instrument is the prerequisite for a widespread implementation.

In Denmark and specifically in our department there is a need for an easy to use Danish version of the $\mathrm{Nu}$ DESC, especially since it has been recommended in the 2017 guidelines of the European Society of Anaesthesiologists on postoperative delirium [12].

Often the quality of data gathered through translated measurement instruments is dependent of the translation process [21]. It is worth noting the inconsistency and lack of methodology of the majority of translations in this field.

We therefore support the ISPOR principles [21]. Only systematic procedures and subsequent evaluations can produce valid and reliable measurement instruments.

As a limitation to our study the lack of a DSM 5 validation could be stated. However, we did not choose to compare the Nu-DESC DK to DSM IV or DSM 5 criteria because an isolated comparison between the $\mathrm{Nu}$-DESC DK and the "new" DSM 5 criteria did not seem meaningful (other Nu-DESC translations and Delirium tools where only compared to DSM IV) and due to the fact that the whole delirium focus has shifted significantly with the progression of delirium gold standards from DSM IV to DSM 5. Now there is only a $30 \%$ overlap between DSM IV and 5 in delirium diagnosis using the strict definition $[22,23]$. Additionally, the $\mathrm{Nu}$ DESC has been abundantly validated in comparison to DSM IV in numerous different languages and settings [24-28].

An international multicentre validation study according to DSM 5 criteria (strict as well loose interpretation of DSM 5 criteria) would be very helpful. However it was not the primary aim this ISPOR conform translation.

\section{Conclusion}

With the Nu-DESC DK we provide an official Danish delirium screening instrument, which can detect all psychomotor types of delirium. Nu-DESC DK has the potential to be the cornerstone to the screening and diagnosis of delirium in Denmark.

\section{Abbreviations}

ISPOR: International Society for Pharmacoecomonics and Outcome Research; Nu-DESC DK: Nursing Delirium Screening Scale Denmark; Nu-DESC: Nursing Delirium Screening Scale; TCA Group: Translation and Cultural Adaption Group; WHO: World Health Organization

\section{Acknowledgments \\ We would like to thank the nurses and doctors of the department of Anaesthesiology and of the department of Orthopaedics, of Næstved Hospital in Denmark for their help in evaluating the Nu-DESC DK.}

\section{Funding}

There is no funding of the study.

Availability of data and materials

All the data supporting the findings is contained within the manuscript.

\section{Authors' contributions}

$\mathrm{DH}$ and FMR were responsible for the design and coordination. JG gave the permission to translate his screening tool and approved the back translation. DH, FMR, KHTY and THH were responsible for translating the instrument. Jנر was responsible for the back translation. DH, FMR and KHTY performed the cognitive debriefing and analysis. DH, FMR and KHTY performed the drafting of the manuscript. All authors read and approved the final manuscript.

Ethics approval and consent to participate

Not applicable.

\section{Consent for publication}

Not applicable.

\section{Competing interests}

The authors declare that they have no competing interests.

\section{Publisher's Note}

Springer Nature remains neutral with regard to jurisdictional claims in published maps and institutional affiliations.

\section{Author details}

'Department of Anaesthesiology, Næstved Hospital, Ringstedgade 61, 4700 Næstved, Denmark. ${ }^{2}$ Hospital Management, Næstved Hospital, Næstved, Denmark. ${ }^{3}$ Language- and integration centre, Næstved, Denmark. ${ }^{4}$ Faculty of Pharmacy, Laval University, QC, Québec, Canada. ${ }^{5}$ Department of 
Anaesthesiology and Surgical intensive care medicine, Campus-Virchow-Klinikum and Campus Charité Mitte, Charité Universitätsmedizin Berlin, Berlin, Germany.

Received: 22 July 2017 Accepted: 20 December 2017

Published online: 29 December 2017

\section{References}

1. Ely EW, Siegel MD, Inouye SK. Delirium in the intensive care unit: an underrecognized syndrome of organ dysfunction. Semin Respir Crit Care Med 2001:22(2):115-26.

2. Inouye SK, Bogardus ST, Jr., Charpentier PA, Leo-Summers L, Acampora D, Holford TR, Cooney LM, Jr. A multicomponent intervention to prevent delirium in hospitalized older patients. N Engl J Med 1999, 340(9):669-676.

3. Pandharipande $P$, Jackson J, Ely EW. Delirium: acute cognitive dysfunction in the critically ill. Curr Opin Crit Care. 2005;11(4):360-8.

4. Radtke FM, Franck M, Lendner J, Kruger S, Wernecke KD, Spies CD. Monitoring depth of anaesthesia in a randomized trial decreases the rate of postoperative delirium but not postoperative cognitive dysfunction. $\mathrm{Br}$ J Anaesth. 2013:110(Suppl 1):i98-105.

5. Rasmussen LS, Steinmetz J. Ambulatory anaesthesia and cognitive dysfunction. Curr Opin Anaesthesiol. 2015

6. McCusker J, Cole M, Dendukuri N, Belzile E, Primeau F. Delirium in older medical inpatients and subsequent cognitive and functional status: a prospective study. CMAJ. 2001;165(5):575-83.

7. Saczynski JS, Marcantonio ER, Quach L, Fong TG, Gross A, Inouye SK, Jones RN. Cognitive trajectories after postoperative delirium. N Engl J Med. 2012;367(1):30-9.

8. Francis J, Martin D, Kapoor WN. A prospective study of delirium in hospitalized elderly. JAMA. 1990;263(8):1097-101.

9. Inouye SK. The dilemma of delirium: clinical and research controversies regarding diagnosis and evaluation of delirium in hospitalized elderly medical patients. Am J Med. 1994;97(3):278-88.

10. Marcantonio ER, Flacker JM, Wright RJ, Resnick NM. Reducing delirium after hip fracture: a randomized trial. J Am Geriatr Soc. 2001:49(5):516-22.

11. Postoperative delirium in older adults: best practice statement from the American Geriatrics Society. J American College of Surgeons. 2015;220(2): 136-148.e131.

12. Aldecoa C, Bettelli G, Bilotta F, Sanders RD, Audisio R, Borozdina A, Cherubini A, Jones C, Kehlet H, MacLullich A, et al. European Society of Anaesthesiology evidence-based and consensus-based guideline on postoperative delirium. Eur J Anaesthesiol. 2017;34(4):192-214.

13. Peterson JF, Pun BT, Dittus RS, Thomason JW, Jackson JC, Shintani AK, Ely EW. Delirium and its motoric subtypes: a study of 614 critically ill patients. J Am Geriatr Soc. 2006;54(3):479-84.

14. Meagher DJ, O'Hanlon D, O'Mahony E, Casey PR, Trzepacz PT. Relationship between symptoms and motoric subtype of delirium. J Neuropsychiatry Clin Neurosci. 2000;12(1):51-6.

15. Robinson TN, Raeburn CD, Tran ZV, Brenner LA, Moss M. Motor subtypes of postoperative delirium in older adults. Arch Surg. 2011;146(3):295-300.

16. Inouye SK, Foreman MD, Mion LC, Katz KH, Cooney LM Jr. Nurses' recognition of delirium and its symptoms: comparison of nurse and researcher ratings. Arch Intern Med. 2001;161(20):2467-73.

17. Gaudreau JD, Gagnon P, Harel F, Tremblay A, Roy MA. Fast, systematic, and continuous delirium assessment in hospitalized patients: the nursing delirium screening scale. J Pain Symptom Manag. 2005;29(4):368-75.

18. Wong CL, Holroyd-Leduc J, Simel DL, Straus SE. Does this patient have delirium?: value of bedside instruments. JAMA. 2010;304(7):779-86.

19. Gaudreau JD, Gagnon P, Harel F, Roy MA. Impact on delirium detection of using a sensitive instrument integrated into clinical practice. Gen Hosp Psychiatry. 2005;27(3):194-9.

20. Smith MJ, Breitbart WS, Platt MM. A critique of instruments and methods to detect, diagnose, and rate delirium. J Pain Symptom Manag. 1995;10(1):35-77.

21. Wild D, Grove A, Martin M, Eremenco S, McElroy S, Verjee-Lorenz A, Erikson P. Principles of good practice for the translation and cultural adaptation process for patient-reported outcomes (PRO) measures: report of the ISPOR task force for translation and cultural adaptation. Value Health. 2005;8(2):94-104

22. Meagher DJ, Morandi A, Inouye SK, Ely W, Adamis D, Maclullich AJ, Rudolph $J \mathrm{~L}$, Neufeld K, Leonard M, Bellelli G, et al. Concordance between DSM-IV and
DSM-5 criteria for delirium diagnosis in a pooled database of 768 prospectively evaluated patients using the delirium rating scale-revised-98. BMC Med. 2014;12:164

23. Adamis D, Meagher D, Rooney S, Mulligan O, McCarthy G. A comparison of outcomes according to different diagnostic systems for delirium (DSM-5, DSM-IV, CAM, and DRS-R98). Int Psychogeriatr. 2017:1-6.

24. Poikajarvi S, Salantera S, Katajisto J, Junttila K. Validation of Finnish Neecham confusion scale and nursing delirium screening scale using confusion assessment method algorithm as a comparison scale. BMC Nurs. 2017;16:7.

25. Lingehall HC, Smulter N, Engstrom KG, Gustafson Y, Olofsson B. Validation of the Swedish version of the nursing delirium screening scale used in patients 70 years and older undergoing cardiac surgery. J Clin Nurs. 2013:22(19-20):2858-66.

26. Radtke FM, Franck M, Schneider M, Luetz A, Seeling M, Heinz A, Wernecke KD, Spies CD. Comparison of three scores to screen for delirium in the recovery room. Br J Anaesth. 2008;101(3):338-43.

27. Neufeld KJ, Leoutsakos JS, Sieber FE, Joshi D, Wanamaker BL, Rios-Robles J, Needham DM. Evaluation of two delirium screening tools for detecting post-operative delirium in the elderly. Br J Anaesth. 2013;111(4):612-8.

28. Abelha F, Veiga D, Norton M, Santos C, Gaudreau JD. Delirium assessment in postoperative patients: validation of the Portuguese version of the nursing delirium screening scale in critical care. Brazilian J Anesthesiology (Elsevier). 2013;63(6):450-5.

\section{Submit your next manuscript to BioMed Central and we will help you at every step:}

- We accept pre-submission inquiries

- Our selector tool helps you to find the most relevant journal

- We provide round the clock customer support

- Convenient online submission

- Thorough peer review

- Inclusion in PubMed and all major indexing services

- Maximum visibility for your research

Submit your manuscript at www.biomedcentral.com/submit 